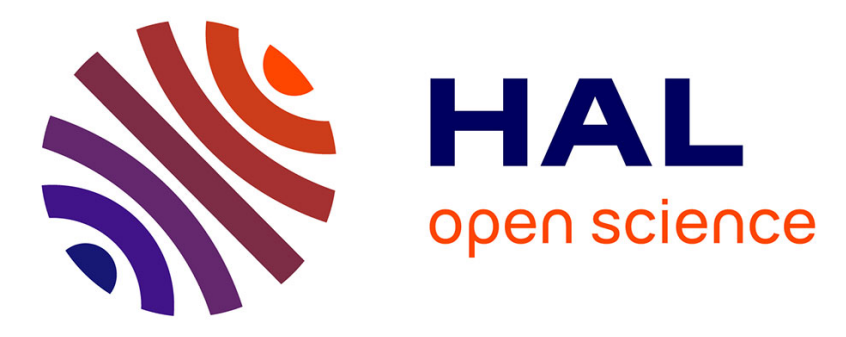

\title{
Sub-surface assessment of hydrothermal ageing in zirconia-containing femoral heads for hip joint applications
}

Laurent Gremillard, Jérome Chevalier, Laura Martin, Thierry Douillard, S. Begand, K. Hans, T. Oberbach

\section{To cite this version:}

Laurent Gremillard, Jérome Chevalier, Laura Martin, Thierry Douillard, S. Begand, et al.. Sub-surface assessment of hydrothermal ageing in zirconia-containing femoral heads for hip joint applications. Acta Biomaterialia, 2018, 68 (3), pp.286 - 295. 10.1016/j.actbio.2017.12.021 . hal-01743312

\section{HAL Id: hal-01743312 \\ https://hal.science/hal-01743312}

Submitted on 30 Apr 2019

HAL is a multi-disciplinary open access archive for the deposit and dissemination of scientific research documents, whether they are published or not. The documents may come from teaching and research institutions in France or abroad, or from public or private research centers.
L'archive ouverte pluridisciplinaire HAL, est destinée au dépôt et à la diffusion de documents scientifiques de niveau recherche, publiés ou non, émanant des établissements d'enseignement et de recherche français ou étrangers, des laboratoires publics ou privés. 


\title{
Sub-surface assessment of hydrothermal ageing in zirconia-containing femoral heads for hip joint applications
}

\author{
Published in Acta Biomaterialia (2018), 68 pp. 289-65 \\ https://doi.org/10.1016/j.actbio.2017.12.021
}

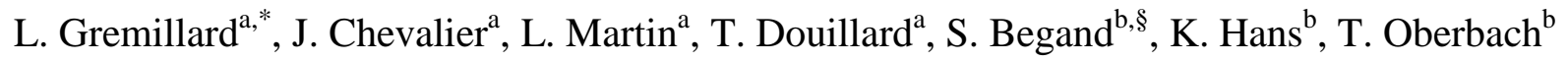 \\ ${ }^{a}$ Univ Lyon, INSA Lyon, CNRS, MATEIS, UMR 5510, F-69621, Villeurbanne, France \\ ${ }^{\mathrm{b}}$ Mathys Orthopaedie GmbH, An den Trillers Bueschen 2, DE-07646 Moersdorf, Germany \\ ${ }^{\S}$ Present address: Head of department: Oxide Ceramics, Fraunhofer Institute for Ceramic \\ Technologies and Systems, Michael-Faraday-Str. 1, DE-07629 Hermsdorf \\ * Corresponding author: laurent.gremillard@insa-lyon.fr, +33472438152
}

\begin{abstract}
Zirconia-based materials have been used in orthopaedics since the 1980s, with large success, mainly thanks to transformation toughening. On the other hand, their main drawback is their potential sensitivity to hydrothermal ageing, i.e. tetragonal to monoclinic phase transformation on their surface in the presence of water. Hydrothermal ageing may result in roughness increase and microcracking of the surface. In this article the hydrothermal ageing behaviour of three medical-grade zirconia-based materials is assessed at high temperature and extrapolated to room or body temperature. The degradation is also characterized by FIB/SEM nano-tomography to better assess sub-surface evolutions. In both zirconia and aluminatoughened zirconia (ATZ), ageing results in the presence of a homogenous transformed layer of constant thickness whose growth rate is about 8 times slower in ATZ than in zirconia. Microcracking occurs in the entire transformed layer in zirconia, but was much less relevant in ATZ. Zirconia-toughened alumina (ZTA) is much less prone to ageing. In ZTA ageing results in a thin transformed layer in which the monoclinic fraction decreases with depth. No microcracking was observed in ZTA.
\end{abstract}

\section{Keywords}

Zirconia; Hydrothermal ageing; FIB-SEM; XRD 


\section{Introduction}

Zirconia, precisely the Tetragonal Zirconia Polycrystal stabilized by 3 mol. $\% \mathrm{Y}_{2} \mathrm{O}_{3}$ (3Y-TZP) was introduced in orthopaedics in the early 1990s for the fabrication of femoral heads for total hip arthroplasty. Indeed, this material is the monolithic oxide ceramic presenting the highest fracture strength (up to $1.5 \mathrm{GPa}$ ). Despite concerns over roughening and wear issues observed on explanted heads in the late 1990s, it was continuously used until 2001, when a few hundred zirconia heads fractured within two years of implantation. These early failures could be related to the tetragonal to monoclinic $(\mathrm{t}-\mathrm{m})$ phase transformation inherent to zirconia ceramics. Indeed, $\mathrm{t}-\mathrm{m}$ phase transformation in the vicinity of a propagating crack is the origin of phase transformation toughening [1, 2], explaining the high strength of 3Y-TZP. However, as first described by Kobayashi in 1984 [3], it is known that zirconia ceramics are prone to a degradation mechanism referred to as "hydrothermal ageing" or "Low Temperature Degradation" (LTD). This mechanism also implies t-m phase transformation, on the surfaces exposed to humidity. It results in increased roughness of the exposed surfaces (reduced wear resistance) and microcracking (due to the high volume increase of 4-6\% associated with the t$\mathrm{m}$ transformation). Some yttria-stabilized zirconia materials such as fully-stabilized zirconia (stabilized in the cubic phase) do not suffer from hydrothermal ageing since they contain no tetragonal phase. However their mechanical properties are not high enough to warrant their use in orthopaedics [4].

The consequences of hydrothermal ageing of 3Y-TZP ceramics are well documented, both from laboratory studies [5-12] and clinical feedbacks [13-17].

Conversely, only few studies exist on hydrothermal ageing of the more recent zirconiatoughened alumina (ZTA) materials, comprised of zirconia grains dispersed in an alumina matrix [5, 6, 18-22]. ZTA might present also an ageing phenomenon related to the decomposition of alumina into $\mathrm{AlOOH}$ or $\mathrm{Al}(\mathrm{OH})_{3}[23,24]$. However this effect is neglected here, since previous work has shown that no detectable mass loss was taking place in ZTA femoral heads submitted to hydrothermal ageing [5].

Most of the available studies dealing with hydrothermal ageing of ZTA highlight the reduced roughening of ZTA compared to $3 \mathrm{Y}-\mathrm{TZP}$ [18, 20, 21], making the consequences of hydrothermal ageing much less problematic for ZTA. These findings seem to be corroborated by the few available studies on explanted ZTA components [25-27] that specifically examine this point. The literature on hydrothermal ageing of Alumina-Toughened Zirconia (ATZ), consisting of alumina grains dispersed in a zirconia matrix is even less extended [28-31], and the authors could find no paper examining the hydrothermal ageing on explanted ATZ components. Moreover, majority of studies are conducted on flat samples, that do not perfectly reproduce the surface characteristics (roughness, residual stresses) of implanted components.

Therefore, the aim of the current evaluation is to characterize hydrothermal ageing on readyto-implant hip prostheses heads made of two biomedical grade zirconia-based materials (ZTA and ATZ). The ageing kinetics are measured at different temperatures, allowing an estimation at body temperature. The microstructural evolutions on the first few microns below the surface are assessed, from the point of view of the phases present in the material and of the micro-cracking, and compared to a reference material (3Y-TZP). 


\section{Materials and methods}

\subsection{Materials}

The tests were conducted on $32 \mathrm{~mm}$ femoral heads used for hip prostheses, made of aluminatoughened zirconia (ATZ, ceramys ${ }^{\circledR}$, composed of $80 \mathrm{wt} . \% 3 \mathrm{Y}$-TZP and $20 \mathrm{wt} . \% \alpha-\mathrm{Al}_{2} \mathrm{O}_{3}$, i.e. 72.4 and 27.6 vol.\% respectively) and zirconia-toughened alumina (ZTA, symarec®, composed of 75 wt. $\% \alpha-\mathrm{Al}_{2} \mathrm{O}_{3}$ and , 25 wt.\% 3 Y-TZP - i.e. 82 and 18 vol.\% respectively) processed by Mathys Orthopaedie GmbH. No 3Y-TZP heads were available. ATZ, ZTA and $3 \mathrm{Y}$-TZP polished disks ( $25 \mathrm{~mm}$ diameter, $2 \mathrm{~mm}$ thickness, polished to a Ra between 10 and $17 \mathrm{~nm}$, measured by a tactile profilometer (HOMMEL-ETAMIC T8000, JENOPTIK)) were also used for some of the measurements presented below.

\subsection{Hydrothermal ageing}

The sensitivity to hydrothermal ageing of the different materials was assessed on $32 \mathrm{~mm}$ diameter hip prostheses balls, by measuring the fraction of monoclinic zirconia phase after accelerated ageing in water vapour in autoclave, between $90^{\circ} \mathrm{C}$ and $134^{\circ} \mathrm{C}$ (Wolf Sanoclav LA-MCS, Germany, using deionised water). The monoclinic fraction was measured by X-ray diffraction (XRD), using a Bruker D8 diffractometer in Bragg-Brentano configuration and with $\mathrm{CuK} \alpha$ radiations, between 27 and $32^{\circ}(2 \theta)$ (step size $0.05^{\circ}, 0.2^{\circ} / \mathrm{min}$.). The monoclinic volume fraction $\mathrm{V}_{\mathrm{m}}$ was calculated according to Garvie and Nicholson equation [32] modified by Toraya [33]:

$$
\mathrm{V}_{\mathrm{m}}=\frac{1.311 \cdot \mathrm{X}_{\mathrm{m}}}{1+0.311 \cdot \mathrm{X}_{\mathrm{m}}}, \text { with } \quad \mathrm{X}_{\mathrm{m}}=\frac{\mathrm{I}_{\mathrm{m}}^{111}+\mathrm{I}_{\mathrm{m}}^{\overline{1} 11}}{\mathrm{I}_{\mathrm{m}}^{111}+\mathrm{I}_{\mathrm{m}}^{\overline{1} 11}+\mathrm{I}_{\mathrm{t}}^{101}}
$$

where $I_{p}{ }^{h k l}$ is the area of the diffraction peak related to the (hkl) plane of the phase $p$ ( $m$ for monoclinic and t for tetragonal). With the measurement conditions used, the sensitivity of this method is around $1 \%$ for all materials used here.

Ageing kinetics measured by XRD can be well fitted by Mehl-Avrami-Johnson law (Eq. 2, in which $V_{m}$ is the monoclinic phase fraction, $\tau$ the time, $n$ an exponent related to the ratio between nucleation and growth during the $\mathrm{t}-\mathrm{m}$ transformation; $V_{m}{ }^{0}$ and $V_{m}{ }^{\operatorname{Max}}$ being respectively the initial (measured) and maximum monoclinic content). In equation $2, b$ is thermally activated [7]. The activation energy $Q$ was calculated for each materials by measuring the ageing kinetics in water vapour at different temperatures $(90,111,134$ and $143^{\circ} \mathrm{C}$ ) as described in details by Chevalier et al. [34]. This approach enables the extrapolation of ageing kinetics to lower temperatures, in particular to the body temperature. Equation 3, derived from Eq. 2, explains this extrapolation: the same monoclinic fraction is reached for both $\left(\tau_{1}, \mathrm{~T}_{1}\right)$ and $\left(\tau_{2}, \mathrm{~T}_{2}\right)$ conditions (in these equations, $\tau$ is the ageing duration and $\mathrm{T}$ is the absolute temperature of ageing, $\mathrm{R}$ is the perfect gas constant).

$$
\begin{gathered}
\mathrm{V}_{\mathrm{m}}(\tau)=\mathrm{V}_{\mathrm{m}}^{0}+\left(\mathrm{V}_{\mathrm{m}}^{\mathrm{Max}}-\mathrm{V}_{\mathrm{m}}^{0}\right)\left(1-\exp \left[-(\mathrm{b} . \tau)^{\mathrm{n}}\right]\right), \text { with } \mathrm{b}=\mathrm{b}_{0} \exp \left[-\frac{\mathrm{Q}}{\mathrm{RT}}\right] \quad \text { Eq. } 2 \\
\tau_{2}=\tau_{1} \exp \left[\frac{\mathrm{Q}}{\mathrm{R}}\left(\frac{1}{\mathrm{~T}_{2}}-\frac{1}{\mathrm{~T}_{1}}\right)\right] \quad \text { Eq. } 3
\end{gathered}
$$


The depth profile of transformation below the surface was also evaluated by X-ray diffraction, using a technique described in a past study [35]. Measurements of the depth profile could not be conducted on heads. Instead they were conducted on flat polished disks aged up to $100 \mathrm{~h}$ at $134^{\circ} \mathrm{C}$. First monoclinic depth profiles were measured on all three materials after 0,10 and $50 \mathrm{~h}$ ageing at $134^{\circ} \mathrm{C}$. For Y-TZP, since saturation of monoclinic fraction was almost reached at $50 \mathrm{~h}$, an intermediate point was taken at $24 \mathrm{~h}$. For ATZ, at $50 \mathrm{~h}$ the monoclinic fraction reached $\sim 50 \%$ of the saturation level, thus two more points were taken at 65 and $100 \mathrm{~h}$.

Briefly, scans were acquired at different, fixed incidence angles $\left(\theta_{\mathrm{i}}=0.5,1,2,5,10\right.$ and 15 deg). The transformation profile $f_{m}(z)$ was then deduced from the evolution of $X_{m}$ with the incidence angle. To use this technique, it is convenient to introduce the "reciprocal depth" $u$ given by Eq. 4 with the substitution:

$$
u=\frac{2 \mu \rho \sin \left(\theta_{b}\right) \cos \left(\theta_{b}-\theta_{i}\right)}{\sin \left(\theta_{i}\right) \sin \left(2 \theta_{b}-\theta_{i}\right)} \quad \text { Eq. } 4
$$

( $\mu \rho$ is the linear absorption coefficient, considered as independent on the amount of monoclinic phase, $\theta_{b}$ and $\theta_{i}$ are the Bragg angle and the incidence angle respectively). From the Beer - Lambert law and the geometry of the experiment, the depth of analysis $D$ (depth contributing for a fraction $S$ to the diffracted intensity) is related to $u$ by:

$$
D=\frac{-\ln (1-S)}{u} \quad \text { or } \quad u=\frac{-\ln (1-S)}{D} \quad \text { Eq. } 5
$$

Note that in all that follows, $X_{m}(D)$ or $X_{m}(u)$ refer to the average monoclinic fraction over a total depth $D$ (or a reciprocal depth $u$ ), whereas $f_{m}(z)$ refers to the actual monoclinic fraction at a given depth $z$.

The equation chosen to describe $f_{m}(\mathrm{z})$ (monoclinic fraction at a given depth $z$ ) depends on the mathematical equation used to describe the evolution of $X_{m}$ with the reciprocal depth $(u)$. Since different fitting equations can give quite similar errors, two sets of equations were used for each material and each ageing time, one modelling a gradient of monoclinic phase (expressed by an exponential decay combined or not with a linear growth for the small depths) and the second expressing a step in monoclinic fraction in a given depth range.

Supposing an exponential decay for $f_{m}$, the transformation profiles in ZTA were fitted with the following equations (Eq. 6, in which $a$ and $u_{0}$ are fitting variables):

$$
\begin{aligned}
\frac{X m(u)}{u}=\frac{a u}{\left(u+u_{0}\right)^{2}}, \text { with } u=\frac{\ln (10)}{z} & \text { Eq. 6(a) } \\
f m(z)=a \exp \left(-u_{0} z\right) & \text { Eq. 6(b) }
\end{aligned}
$$

Still for the exponential behaviour, for a simple exponential decay could not be applied for ATZ and 3Y-TZP. For these materials the profiles had to be fitted so that $f_{m}$ first increases from 0 , then decays exponentially. The equations 7(a) and 7(b) were used (with $b$ and $u_{0}$ as fitting variables):

$$
\begin{array}{ll}
\frac{X m(u)}{u}=\frac{b}{\left(u+u_{0}\right)^{2}} & \text { Eq. 7(a) } \\
f m(z)=b z \exp \left(-u_{0} z\right) & \text { Eq. 7(b) }
\end{array}
$$

However, for 3Y-TZP after 50 hours ageing and ATZ after 100h of ageing, these previous equations were not adequate, and instead the profiles could be fitted with equations 8(a) and 8(b), that modulate the exponential decay (with $c, u_{0}$ and $u_{1}$ the fitting variables): 


$$
\begin{array}{ll}
\frac{X m(u)}{u}=\frac{c}{\left(u+u_{0}\right)\left(u+u_{1}\right)} & \text { Eq. 8(a) } \\
f m(z)=\frac{c}{u_{1}-u_{0}}\left[\exp \left(-u_{0} z\right)-\exp \left(-u_{1} z\right)\right] & \text { Eq. 8(b) }
\end{array}
$$

It should be noted that Eq. 7(a) and 7(b) are respectively the limiting cases of Eq. 8(a) and 8(b) when $u_{l}=u_{0}$. Indeed, fits attempted on all other ATZ and 3Y-TZP materials with eq. 8(a) gave precisely this result and thus are not shown here.

For the "step" behaviour, the equations used were Eq. 9(a) and 9(b), $f_{m 0}, z_{1}$ and $z_{2}$ being the fitting variable, with $0 \leq z_{1} \leq z_{2}$ :

$$
\begin{array}{ll}
\frac{X m(u)}{u}=\frac{f_{m 0}}{u}\left(e^{-z_{1} u}-e^{-z_{2} u}\right) & \text { Eq. 9(a) } \\
f_{m}= \begin{cases}0 \text { if } z<z_{1} & \text { Eq. 9(b) } \\
f_{m 0} \text { if } z_{1} \leq z \leq z_{2} & \\
0 \text { if } z>z_{2} & \end{cases}
\end{array}
$$

\subsection{Microstructural analyses}

The capabilities of FIB/SEM's upgraded with in situ gas injection system (GIS) have been widely reviewed over recent years. In material science, preparation of cross-sections is a usual application of such well-equipped instruments. FIB cross sectioning associated with SEM imaging is well suited to determine the extent of monoclinic transformation.

The original concept of sequential slicing tomography can also be achieved in these so called double-column systems: once a region of interest has been selected in the sample, it is milled layer by layer with the ion beam, and electronic images are successively taken from each fresh milled section with the SEM. In a second phase, all slices are assembled in a stack, after a few steps of image processing, to represent the volume of matter or rather segmented elements of the microstructure.

The FIB/SEM tomography method has demonstrated the ability to provide volumetric data with a voxel dimension down to a few nanometers which justifies the designation of Focused Ion Beam nano-tomography (FIB-nt). Thus, FIB-nt method covers spatially-resolved volumes not available with other 3D characterization technique. We have taken advantage of this technique to evaluate the volume content of porosity and alumina grains and to have information on the micro-crack network associated to the transformation.

Experiments were performed using a FIB/SEM workstation (NVision 40; Carl Zeiss Microscopy GmbH, Oberkochen, Germany) combining a SIINT zeta FIB column (Seiko Instruments Inc. NanoTechnology, Japan) with a Gemini I column. The NVision 40 platform is also equipped with a multi-nozzle SIINT gas injection system (GIS).

Special care was taken during all FIB experiments to minimise curtain effect and surface implantation, and to avoid any ion beam induced monoclinic transformation. Prior to serial sectioning, a sufficient cross-sectional surface was freed to minimise as much as possible the shading effects. To perform this step, coarse ion beam currents ranging from $13 \mathrm{nA}$ to $3 \mathrm{nA}$ at $30 \mathrm{keV}$ were used. Then, careful milling at 30keV/700pA was applied for serial sectioning. FIB-nt of ATZ was done with a voxel size of $5 \mathrm{~nm} \times 5 \mathrm{~nm} \times 10 \mathrm{~nm}$ whereas this voxel size was set to $(10 \mathrm{~nm})^{3}$ for $3 \mathrm{Y}-\mathrm{TZP}$ and ZTA. Whatever the experience, simultaneous Secondary Electron imaging and Energy filtered Backscattered Electron imaging were performed with an accelerating voltage of $1.5 \mathrm{keV}$. All FIB experiments were conducted on disks. 
Image analysis was then conducted with the FIJI software. First voids were assigned to a phase using segmentation. Then a morphological parameter was used to discriminate pores from cracks: for each void a sphericity criterion $\left(S_{\mathrm{p}}\right)$ was calculated, defined as: $S_{p}=6 V \sqrt{\frac{\pi}{S^{3}}}$

(where $\mathrm{S}$ is the surface of a void and $\mathrm{V}$ its volume); $\mathrm{S}_{\mathrm{p}}$ is 1 for a sphere, less otherwise. This filter is avalaible in the FIJI plugin 3D analysis[36]. The continuity $(\mathrm{C})$ or intra-connectivity of the microcracks was determined by a counting procedure detecting the $3 \mathrm{D}$ independent ensemble of connected voxels [37]. The intra-connectivity was then quantified as the volume fraction of the most voluminous cluster of this material/phase in the analyzed volume.

\subsection{Statistics}

All monoclinic fraction measurements were conducted at least in triplicate (at least 3 samples from the same batch aged in the same conditions). Results on monoclinic fraction are given as average plus or minus one standard deviation.

Numerical fits of the data were performed using Golden Software Gapher 12. For each fit, a $95 \%$ confidence interval was calculated, to calculate the uncertainty on each fitting parameter. Orders of magnitude of these uncertainties are provided in the figures or tables captions when necessary.

\section{Results}

\subsection{Hydrothermal ageing kinetics}

The ageing kinetics at different temperatures are reported on Figure 1 for ATZ and ZTA.

By fitting these experimental results by an Avrami law, any monoclinic content at any time and temperature can now be estimated using equations 2 and 3. The parameters obtained from the data are summarized in Table 1, and allow the extrapolation of the ageing kinetics at $37^{\circ} \mathrm{C}$ as shown in Figure 1. In ZTA, the small quantity of zirconia in the material and the small monoclinic fractions measured for ZTA lead to high relative uncertainties, and thus at least two sets of parameters are equally available for ZTA (depending on the fitting procedure: ZTA(1) (for which each measurement point was given an equal weight in the fitting procedure) and ZTA(2) (for which the measured kinetics at each temperature was given an equal weight), and reported also in Table 1. From these parameters, one can deduce that 1 year ageing in vivo (at $37^{\circ} \mathrm{C}$ ) can be simulated by autoclaving at $134^{\circ} \mathrm{C}$ for about 1.3 hours (for ATZ) or 71 to 87 hours (for ZTA, resp. with parameters ZTA(1) and ZTA(2)).

Table 1: Parameters of the monoclinic content evolution. Relative uncertainties on $n, b_{0}$ and $Q$ are about $5 \%$.

\begin{tabular}{cccc}
\hline & ATZ & ZTA(1) & ZTA(2) \\
\hline $\mathbf{V}_{\mathbf{m}}{ }^{\mathbf{0}}$ & $0.013 \pm 0.01$ & $0.017 \pm 0.01$ & $0.015 \pm 0.01$ \\
$\mathbf{V}_{\mathbf{m}}^{\text {Max }}$ & $0.75 \pm 0.03$ & $0.077 \pm 0.01$ & $0.080 \pm 0.01$ \\
$\mathbf{n}$ & 0.98 & 0.48 & 0.45 \\
$\mathbf{b}_{\mathbf{0}}\left(\mathbf{h}^{-\mathbf{1}}\right)$ & $3.7 \cdot 10^{10}$ & $4.9 \cdot 10^{4}$ & $2.6 \cdot 10^{4}$ \\
$\mathbf{Q}\left(\mathbf{k J}^{\mathbf{m o l}} \mathbf{~}^{-\mathbf{1}}\right)$ & 95.3 & 52 & 50 \\
$\begin{array}{c}\mathbf{x} \text { hours at } \mathbf{~ 3 4}{ }^{\circ} \mathbf{C} \text { represent } \\
\mathbf{1} \text { year at 37 }\end{array}{ }^{\circ} \mathbf{C}$ & 1.3 & 71 & 86 \\
\hline
\end{tabular}



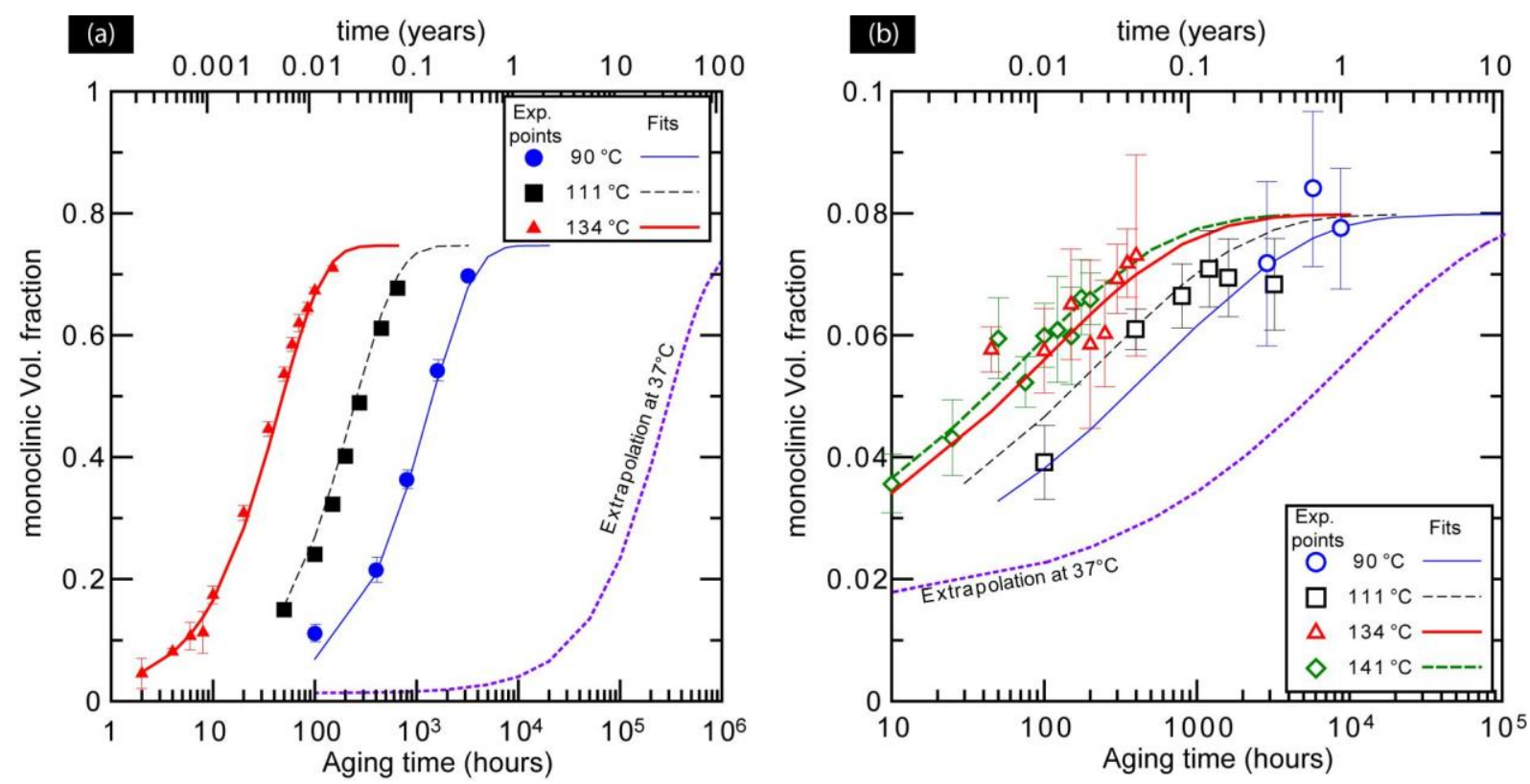

Figure 1: Hydrothermal ageing kinetics in ATZ (a) and ZTA (b) femoral heads (8 XRD measurements for each point). Extrapolations to $37^{\circ} \mathrm{C}$ are also presented (dotted lines).

\subsection{Distribution of the monoclinic phase below the surface from grazing angles experiments}

To gain access to the depth profile distribution of monoclinic phase, following the method exposed in [35], one must first acquire XRD scans with various incidence angles (thus probing various depths) and then fit the evolution of $X_{m}$ (Eq. 1) with a mathematical equation. The depth profile $f_{m}(z)$ obtained with this method are shown in Figure 2 (the choice of the correct profile will be explained in the discussion) together with an example of raw data (measured $\mathrm{X}_{\mathrm{m}} v s$ analysed depth after 50h ageing, in Figure 2 (d)). Figure 3 shows a comparison of the monoclinic depth profiles in the three materials after an identical ageing treatment $\left(50 \mathrm{~h}\right.$ at $\left.134^{\circ} \mathrm{C}\right)$. Due to a larger penetration depth of the X-rays in ZTA (because of the smaller zirconia content), the profiles may be extrapolated to up to 20 microns for this material, in comparison with about 10 microns for Y-TZP and ATZ. However, in the present work this is of no importance since the transformed depth is very small in ZTA. 

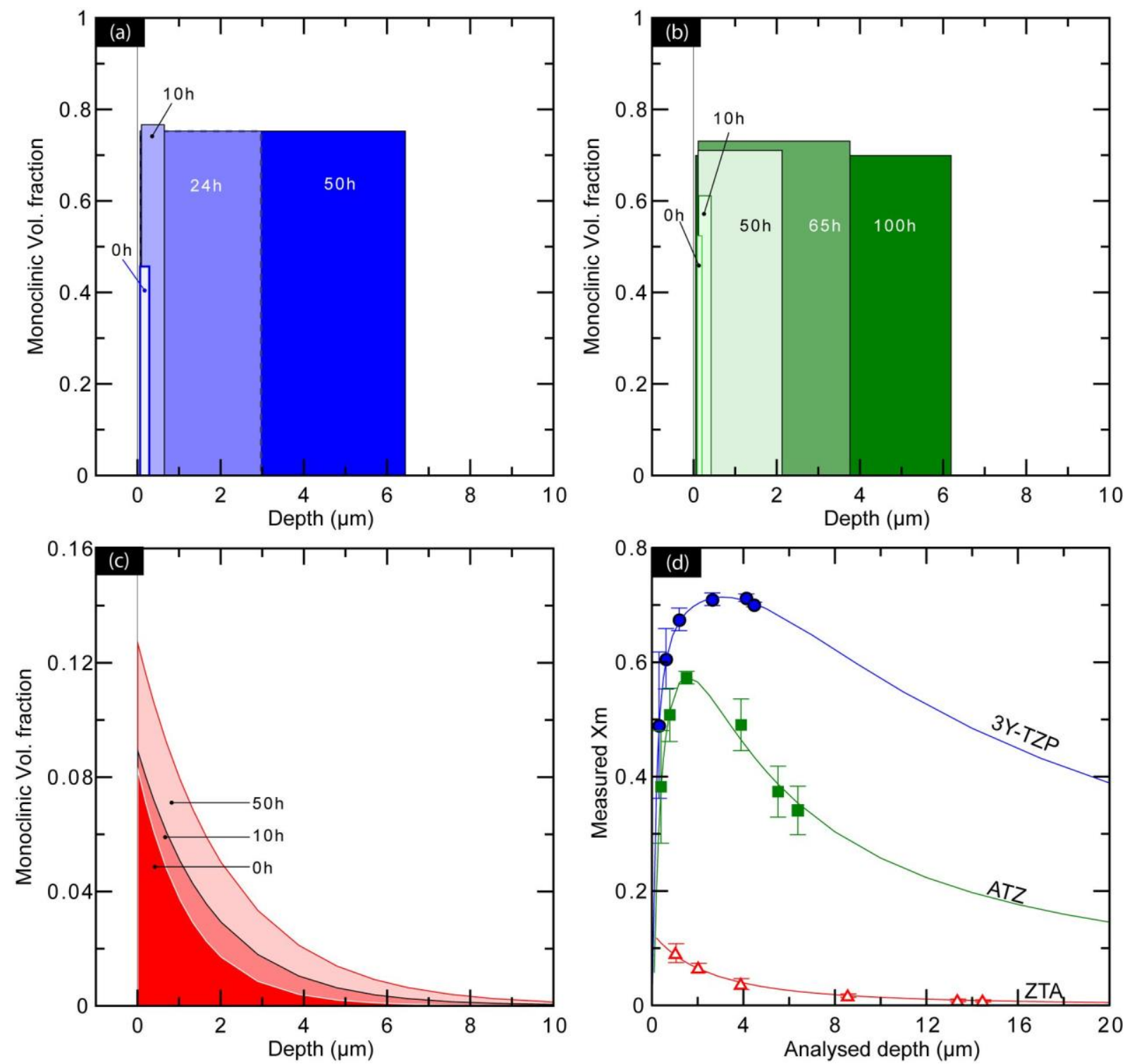

Figure 2: Monoclinic depth profiles $f_{m}(z)$ for the three materials: (a) 3Y-TZP (step behaviour), (b) ATZ (step behaviour), (c) ZTA (exponential behaviour), (d) Raw data (Xm vs analysed depth) at 50h, fitted by eq. 6(a) for ZTA and eq. 9(a) for 3Y-TZP and ATZ.

3Y-TZP exhibits the fastest ageing behaviour of all three materials. Whether one considers the "step behaviour" or the "exponential behaviour", ZTA sets itself apart by the fact that it presents the maximum monoclinic fraction on its surface, whereas for both Y-TZP and ATZ the maximum monoclinic fraction is reached below the surface, implying the existence of a thin non-transformed layer at the surface. ATZ and 3Y-TZP are also similar in the maximum monoclinic fraction they reach (around 0.7) and in the transformed depth (one to a few micrometers), while ZTA presents both a smaller transformed layer (less than $1 \mu \mathrm{m}$ after comparable times) and a lower maximum $\mathrm{m}$-fraction (below 0.15 ). 

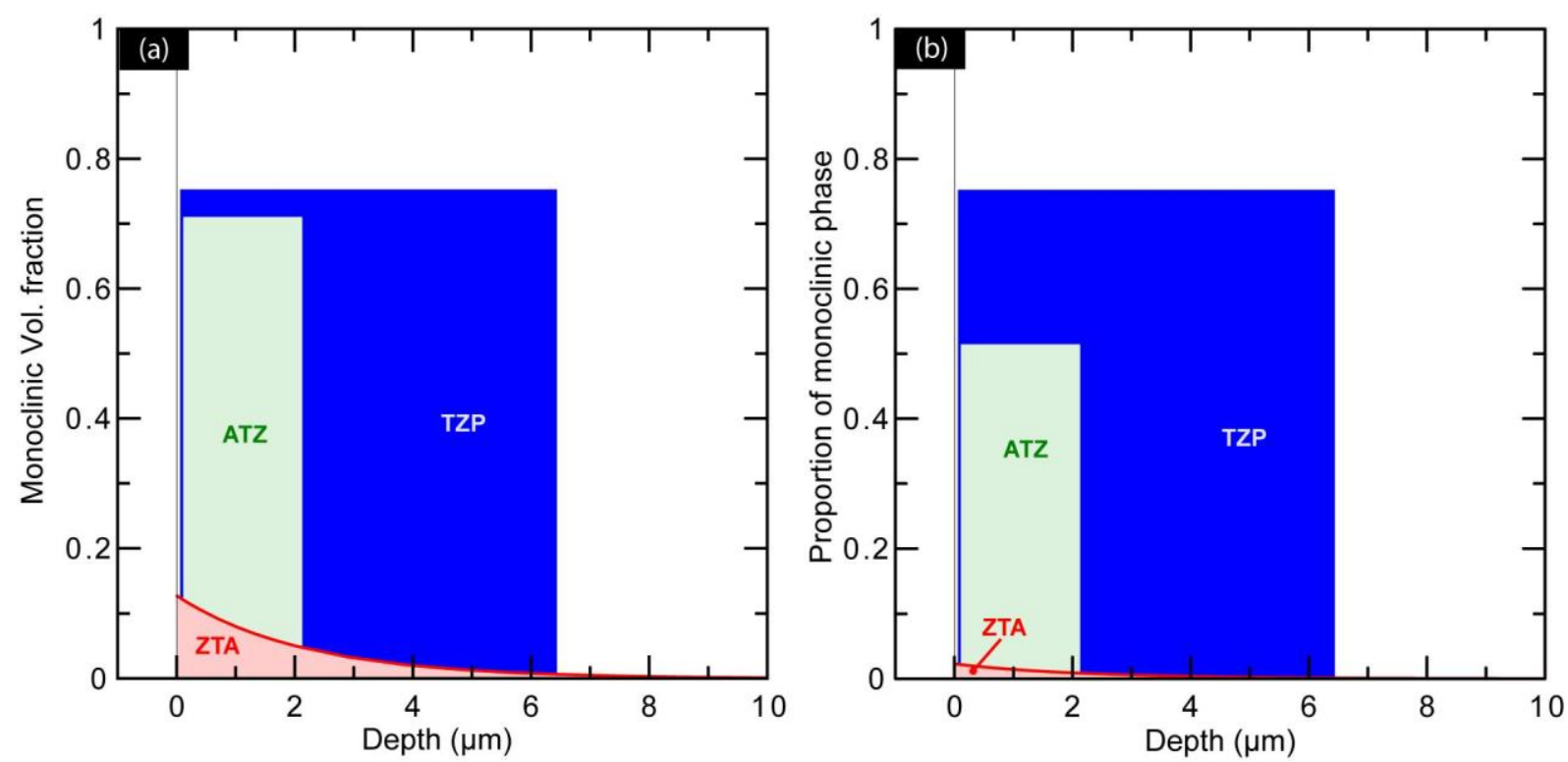

Figure 3 : Comparison of the monoclinic depth profile in ATZ, ZTA and 3Y-TZP after 50h hours ageing in autoclave at $134^{\circ} \mathrm{C}$; (a) monoclinic volume fraction normalized to total zirconia or $(b)$ absolute monoclinic volume fraction.

\subsection{Observation of transformed zones below the surface by FIB}

In order to measure the thickness of the transformed layer, cross-sections obtained by FIB machining were first observed in SEM mode on the three materials after 50h ageing in autoclave at $134^{\circ} \mathrm{C}$. Figure 4 and Figure 5 respectively show this thickness to be around 10 $\mu \mathrm{m}$ for Y-TZP and $5 \mu \mathrm{m}$ for ATZ. Figure 6 shows that the ageing of ZTA does not induce a homogeneous transformed layer, but rather isolated transformed grains; no transformed grain was found below 2 microns under the surface.
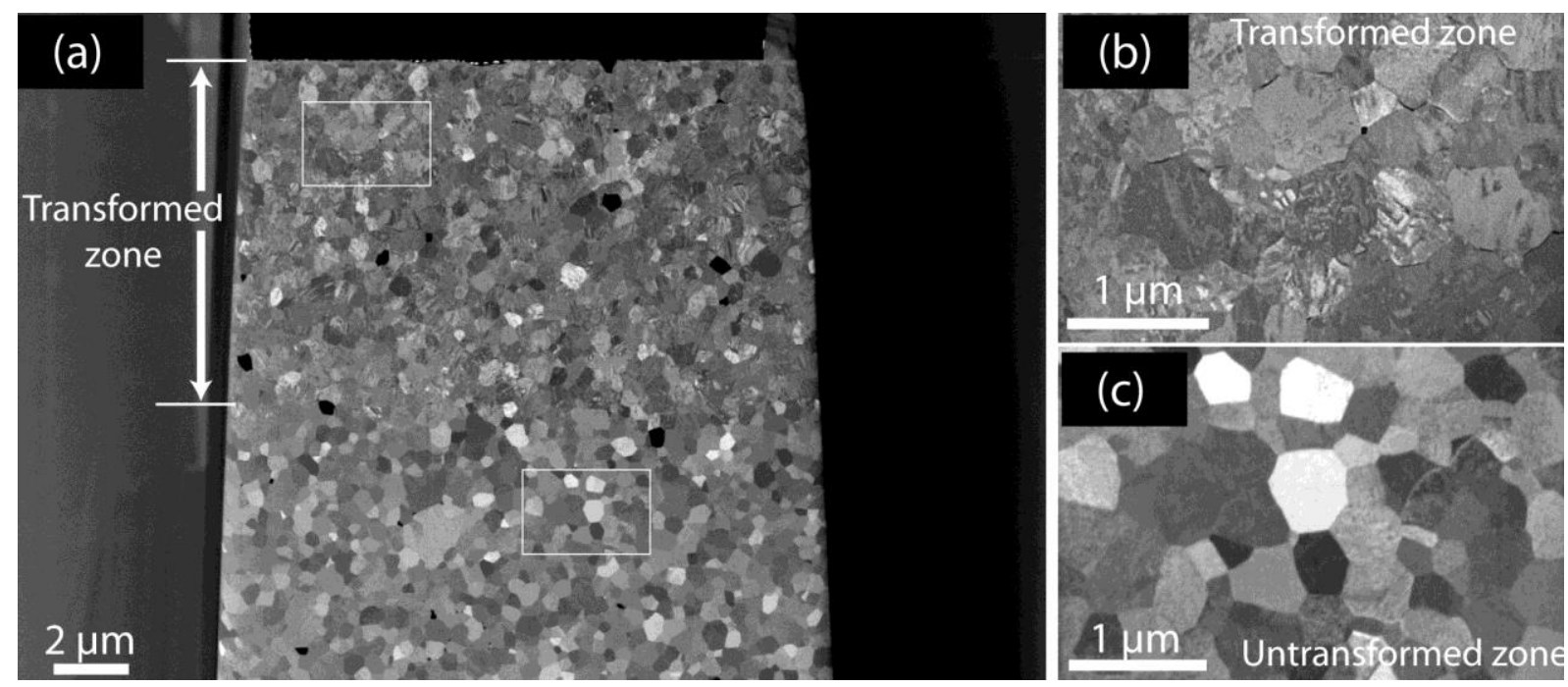

Figure $4: F I B$ cross-section of $3 Y-T Z P$ after 50h ageing in autoclave at $134^{\circ} \mathrm{C}(\mathrm{a})$ : general view; $(b)$ : detail of the transformed zone (microcracks and small pores are visible); (c): detail of the non-transformed zone. On the general view, the transformed, monoclinic zone is indicated by the white arrow; "fuzzy" grains are monoclinic,

black ones are alumina (due the use of the Tosoh E grade, with 0.25 vol.\% of alumina), and the thin boxes indicate the locations of details $(b)$ and $(c)$. In detail $(b)$, the fuzzy or twinned grains are monoclinic. 

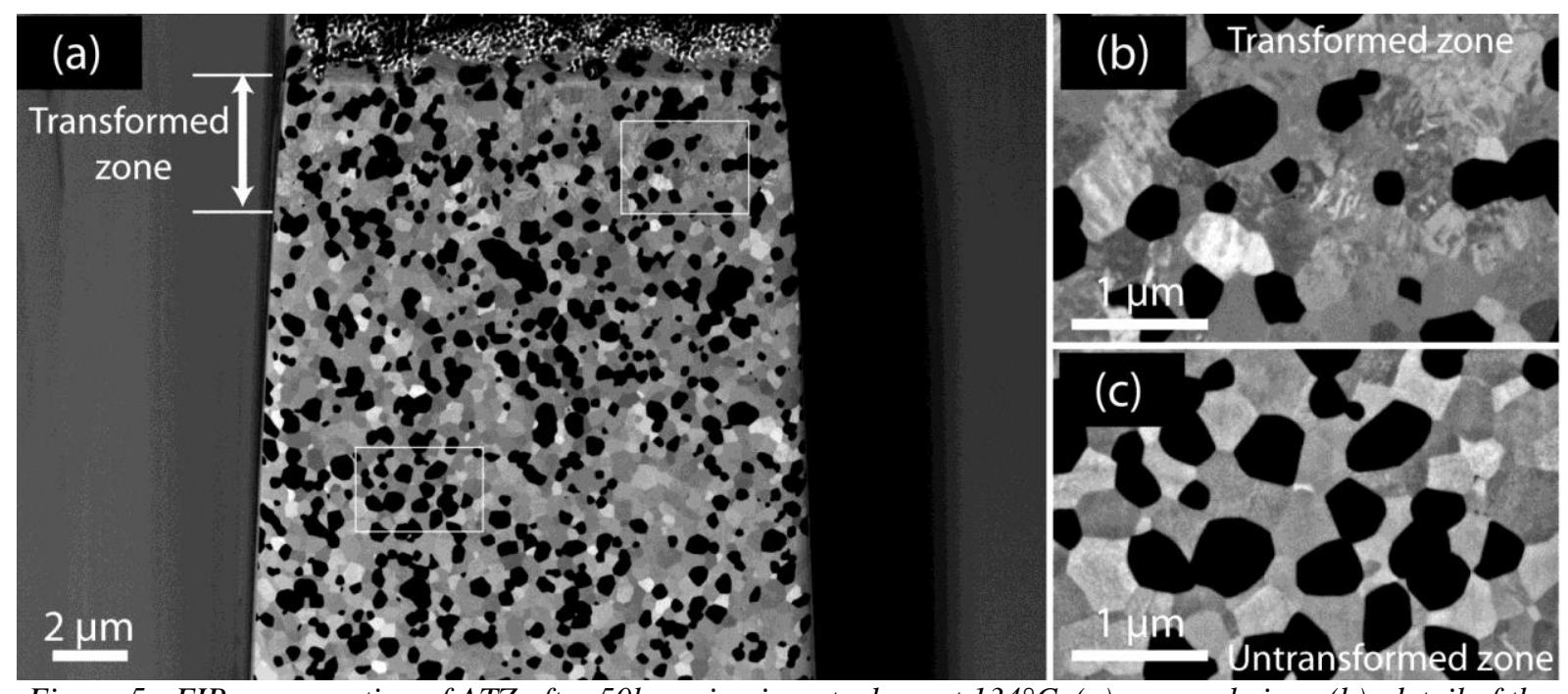

Figure 5 : FIB cross-section of ATZ after $50 \mathrm{~h}$ ageing in autoclave at $134^{\circ} \mathrm{C}$. (a): general view; $(b)$ : detail of the transformed zone (no microcrack is visible); (c): detail of the non-transformed zone. On the general view, the transformed, zone is indicated by the white arrow; "fuzzy" grains are monoclinic, homogeneous grey ones are tetragonal, black ones are alumina, and the thin boxes indicate the locations of details $(b)$ and $(c)$. In detail (b), the fuzzy or twinned grains are monoclinic.
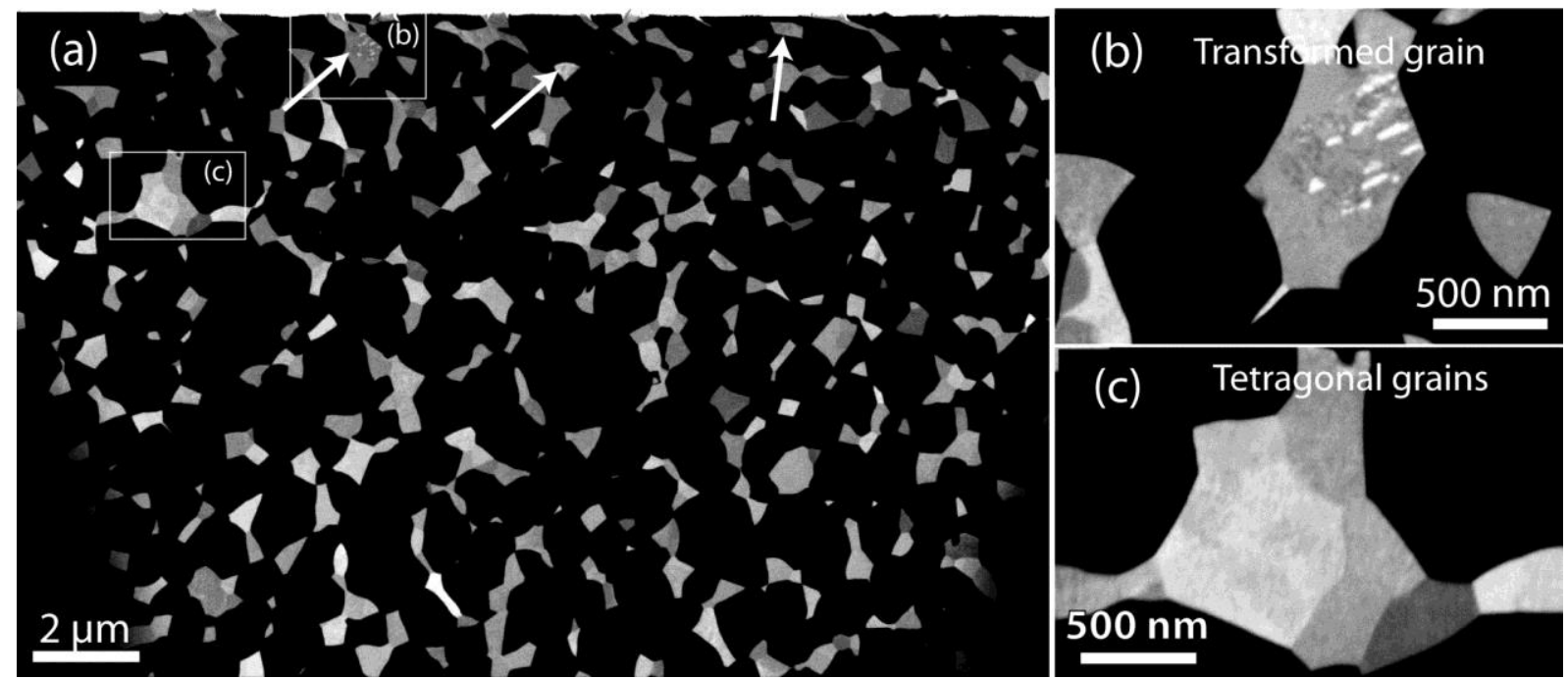

Figure $6:$ FIB cross-section of ZTA after 50h ageing in autoclave at $134^{\circ} \mathrm{C}$. (a): general view (the non-regular upper side of the micrograph is the top surface; white arrows point to transformed grains; the thin boxes indicate the locations of details $(b)$ and $(c)) ;(b)$ : detail of a partially-transformed zone close to the surface; $(c)$ : detail of a non-transformed zone. Black zones are alumina grains, twinned zones are monoclinic.

3D reconstructions were made from series of cross section slides. Then image analysis was used to detect pores and microcracks and to separate zirconia from alumina grains. In 3Y-TZP (Figure 7), the porosity is $0.03 \%$ of the analysed volume, and alumina grains $0.25 \%$. Microcracks are present in the whole transformed volume (up to $10 \mu \mathrm{m}$ under the surface); among the 1652 detected cracks, only one was connected to the surface. In ATZ (Figure 8), the porosity is also $0.03 \%$ of the volume, and alumina grains $27 \%$ (consistent with the starting material). The microcracks are not interconnected, and are limited to the first $3 \mu \mathrm{m}$ (to compare to the $5 \mu \mathrm{m}$ depth monoclinic, transformed zone); only 227 cracks were detected, and 2 of them were connected to the surface. In ZTA (Figure 9), the porosity is around 0.02 vol. \%. No microcracks are detected. Zirconia grains form a completely percolative phase that occupies around $19 \%$ of the volume (again, this is consistent with the starting material). 

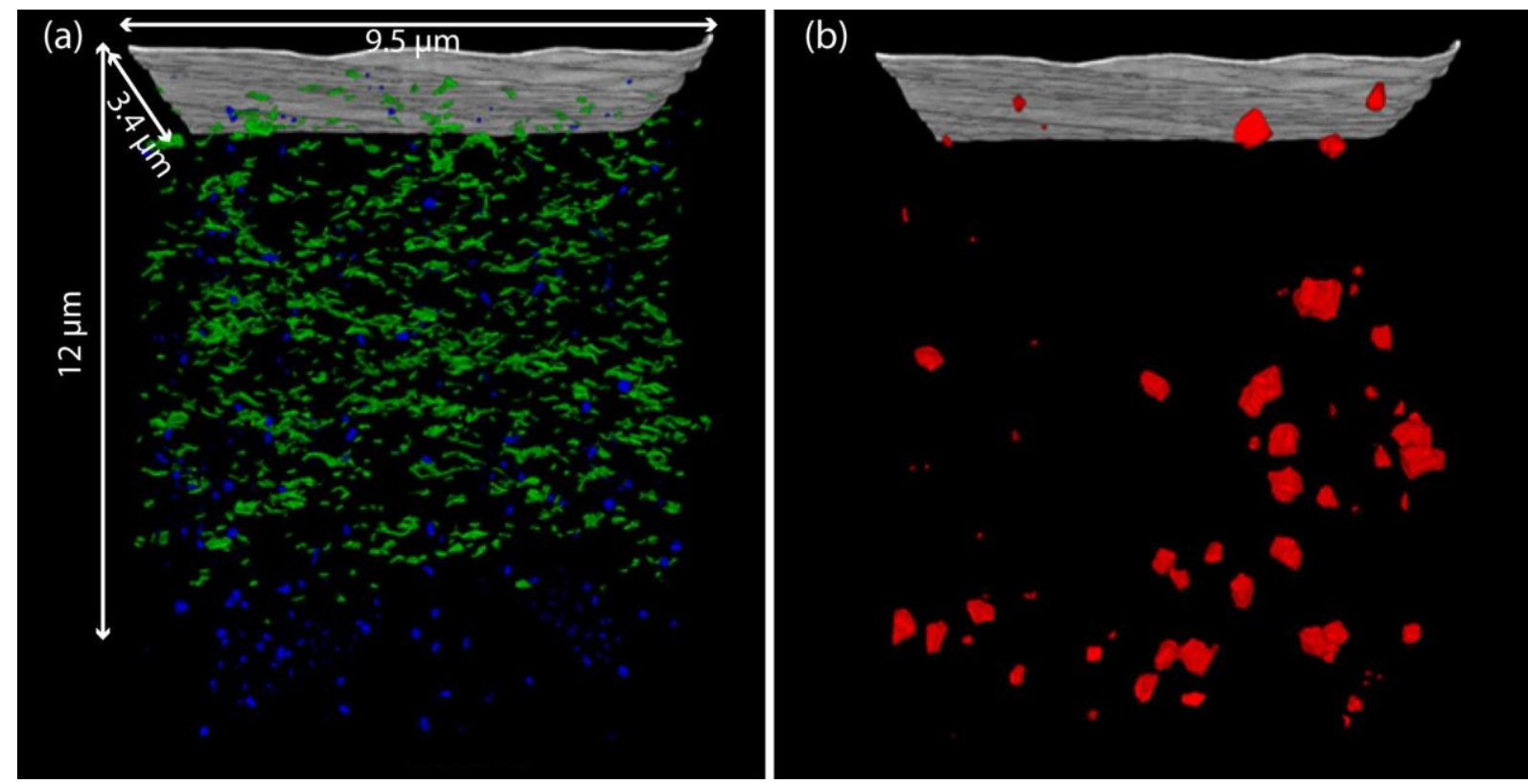

Figure $7: 3 D$ reconstruction by FIB on 3Y-TZP after 50h ageing. Width $x$ Height $x$ Depth: $9.5 \times 12 \times 3.4 \mu m^{3}$; Voxel size: $10 \times 10 \times 10 \mathrm{~nm}^{3}$. Left: Microcracks are shown in green and observed in the whole transformation zone; porosities are seen in blue. Right: alumina shown in red.
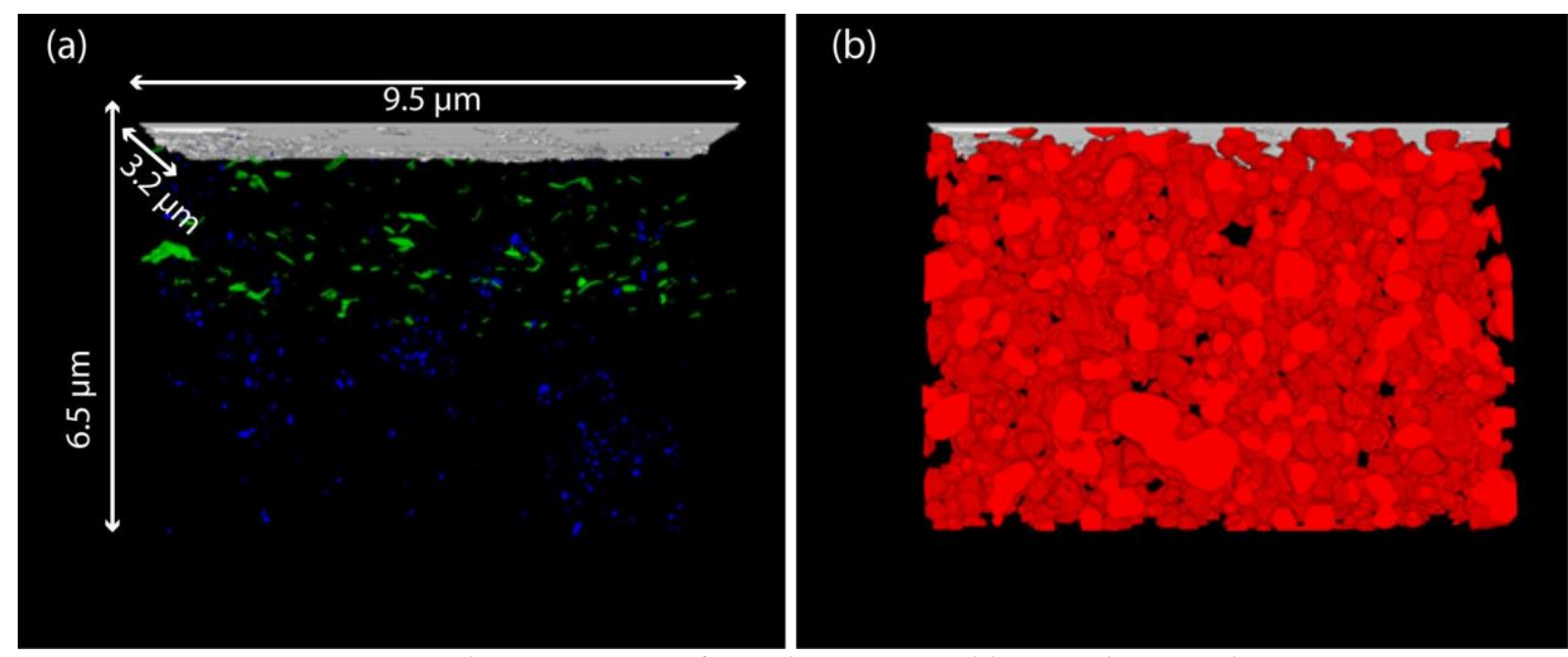

Figure 8: $3 D$ reconstruction by FIB on ATZ after 50h ageing; Width $x$ Height $x$ Depth: $9.5 \times 6.5 \times 3.2 \mu m^{3}$; Voxel size: $5 \times 5 \times 10 \mathrm{~nm}^{3}$. Left: many microcracks are parallel to the surface (in green), but only on the first 3 $\mu \mathrm{m}$ (not on the whole transformed zone); Porosities all over the volume are seen in blue. Right: alumina grains are shown in red and occupy $27 \%$ of the volume. 

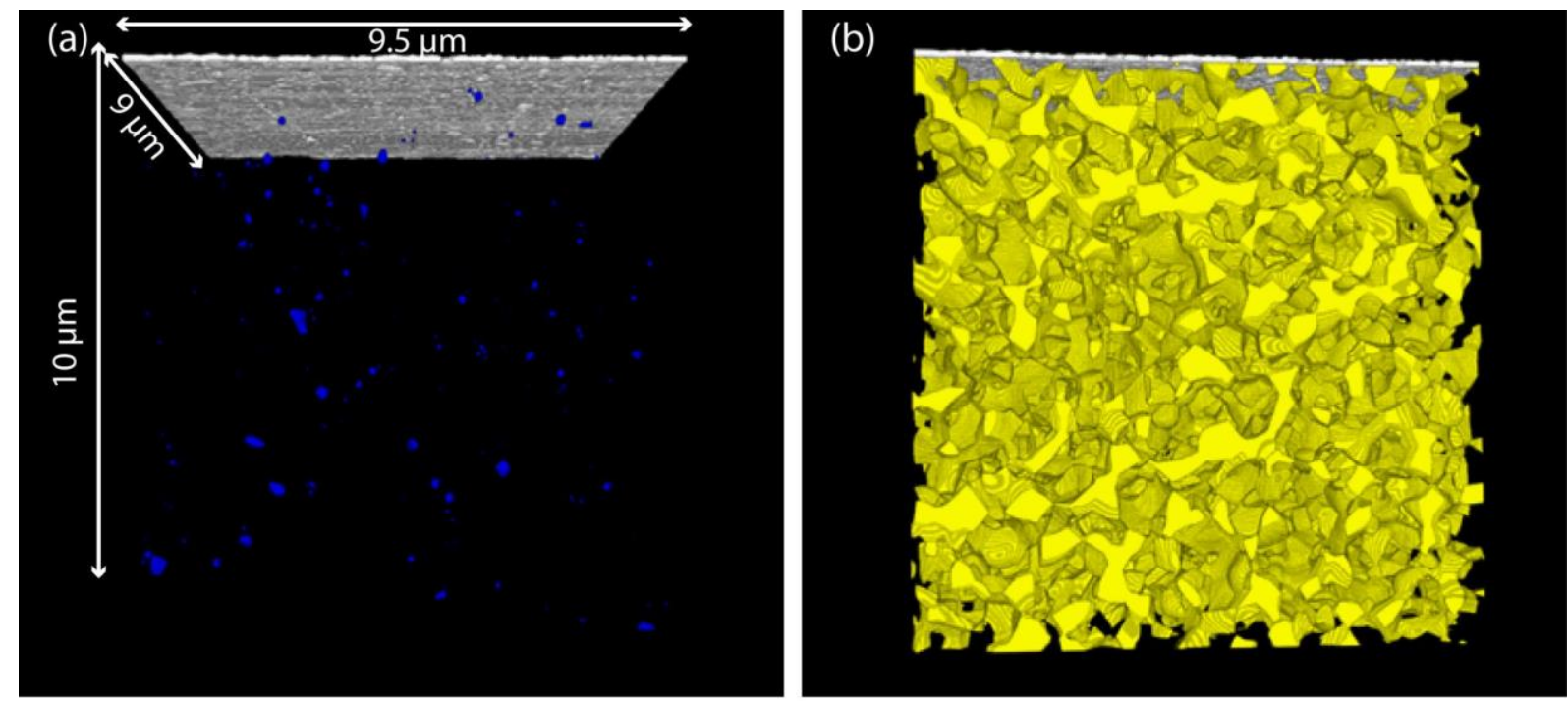

Figure 9:3D reconstruction by FIB on ZTA after 50h ageing; Width $x$ Height $x$ Depth: $9.5 \times 10 \times 9 \mu m^{3}$; Voxel size: $10 \times 10 \times 10 \mathrm{~nm}^{3}$. Left: no microcracks are detected, and only a small number of porosities is seen, homogeneously distributed all over the volume (blue). Right: a completely percolative zirconia phase occupies $19 \%$ of the volume. 


\section{Discussion}

Extrapolations of ageing kinetics at $37^{\circ} \mathrm{C}$ are necessary to predict the t-m transformation associated to hydrothermal ageing in-vivo. However, these are not sufficient to characterize the long-term mechanical properties, and should be coupled with an evaluation of the surface mechanical properties (for example using nano-indentation). While available studies have focused on the microstructural and structural characterisations, this article presents a first step towards this goal, since it uses FIB to evaluate the micro-cracks network appearing on the surfaces following ageing.

The correspondence between extrapolated ageing kinetics at $37^{\circ} \mathrm{C}$ and accelerated ageing at $134^{\circ} \mathrm{C}$ proved to be very different between ATZ and ZTA $\left(1\right.$ year at $37^{\circ} \mathrm{C}$ being simulated by $1.3 \mathrm{~h}$ at $134^{\circ} \mathrm{C}$ for $\mathrm{ATZ}$, or $\sim 80 \mathrm{~h}$ at $134^{\circ} \mathrm{C}$ for ZTA). This large difference between ATZ and ZTA is due to the very different activation energies $(95.3$ and $50-52 \mathrm{~kJ} / \mathrm{mol}$ for ATZ and ZTA respectively). The $95.3 \mathrm{~kJ} \cdot \mathrm{mol}^{-1}$ activation energy found in this study is very similar to the $96.5 \mathrm{~kJ} \cdot \mathrm{mol}^{-1}$ found by Schneider et al. on the same material[28]. However, the value calculated for ZTA is lower than what was already observed for other zirconia-toughened alumina materials (between 70.8 and $108 \mathrm{~kJ} \cdot \mathrm{mol}^{-1}[19,21,38]$ ). It implies a much lower sensitivity of hydrothermal ageing to temperature in the case of this particular ZTA. However, the saturation monoclinic fraction in ZTA is around $8 \%$, meaning that $8 \%$ of the zirconia phase may be transformed to monoclinic phase. This is much lower than the saturation levels found in other ZTA materials with similar composition: between $\sim 15 \%$ and $~ 80 \%$ [39]. Since zirconia is only $25 \%$ of the ZTA material, this corresponds to only $2 \%$ of the total material being transformed to monoclinic on average in the depth of 5 microns accessible to X-Ray diffraction, the bulk being free of monoclinic phase as shown on Figure 6. Thus the expected impact of ageing on this ZTA material should be very low.

A comparison of the ageing kinetics of ATZ and 3Y-TZP is more difficult, since no zirconia heads were available during this study to establish the time-temperature equivalence. However, a comparison with the work by Chevalier et al. [34] shows that ageing in ATZ is slower by a factor of almost eight compared to ageing in $3 \mathrm{Y}-\mathrm{TZP}$, when considering the kinetics extrapolated at $37^{\circ} \mathrm{C}$. For instance, at $37^{\circ} \mathrm{C}$ saturation is reached at $\sim 1.3 \cdot 10^{5}$ hours (15 years) for $3 \mathrm{Y}-\mathrm{TZP}$ in [34], whereas it is reached at $\sim 10^{6}$ hours ( 115 years) for ATZ in this work.

Table 2: total fitting errors in the three materials for the two fits.

\begin{tabular}{ccc}
\hline Material & $\begin{array}{c}\text { Error, } \\
\text { "Exp." behaviour }\end{array}$ & $\begin{array}{c}\text { Error, } \\
\text { "Step" behaviour }\end{array}$ \\
\hline ATZ & $10.9 \cdot 10^{-3}$ & $2.1 \cdot 10^{-3}$ \\
3Y-TZP & $16.1 \cdot 10^{-3}$ & $1.2 \cdot 10^{-3}$ \\
ZTA & $4.8 \cdot 10^{-5}$ & $7.6 \cdot 10^{-5}$ \\
\hline
\end{tabular}

The choice of a mathematical model fitting the depth profile of the transformation is not easy, since for all materials both models give physically reasonable solutions. However, a few considerations can help:

1- The total fitting errors can be calculated as the sum of the squares of the differences between observed $X_{m}$ and calculated $X_{m}$, as reported in Table 2. They indicate that the step behaviour seems more adequate for ATZ and 3Y-TZP, with fitting errors lower by a factor of 5 to 8 , while the exponential fit is slightly better for ZTA. These data are coherent with FIB observations. 
2- A monoclinic zone cannot transform back to tetragonal during hydrothermal ageing. This definitely rules out the exponential behaviour for ATZ and 3Y-TZP, since for both materials the maximum transformation would be lower for the longest ageing time than for the previous one. This also rules out the step behaviour for ZTA, in which the maximum transformation amount would decrease between the first and the second point (Figure 2(d)).

Table 3: parameters of the phase transformation depth profile.

Parameters for the step profile:

z1: thickness of the non-transformed, top layer; $z$ : end of the monoclinic layer; fm0: monoclinic fraction in the monoclinic layer (parameters of Eq. 9). Parameter for the exp. profile: $f_{m}$ max: maximum monoclinic fraction; $Z$ $\left(f_{m}\right.$ max $\left./ 10\right)$ : depth where the monoclinic fraction is one tenth of the maximum monoclinic fraction; $f_{0}$ is the maximum monoclinic fraction (on the surface, parameter a in Eq. 6) and $z_{0}$ relates to the transformation depth (equal to $\ln (10) / u_{0}$ in eq. 6). Relative uncertainties on $z_{1}$ and $z_{2}$ are about $5 \%$. Absolute uncertainties on monoclinic fractions are around $1 \%$.

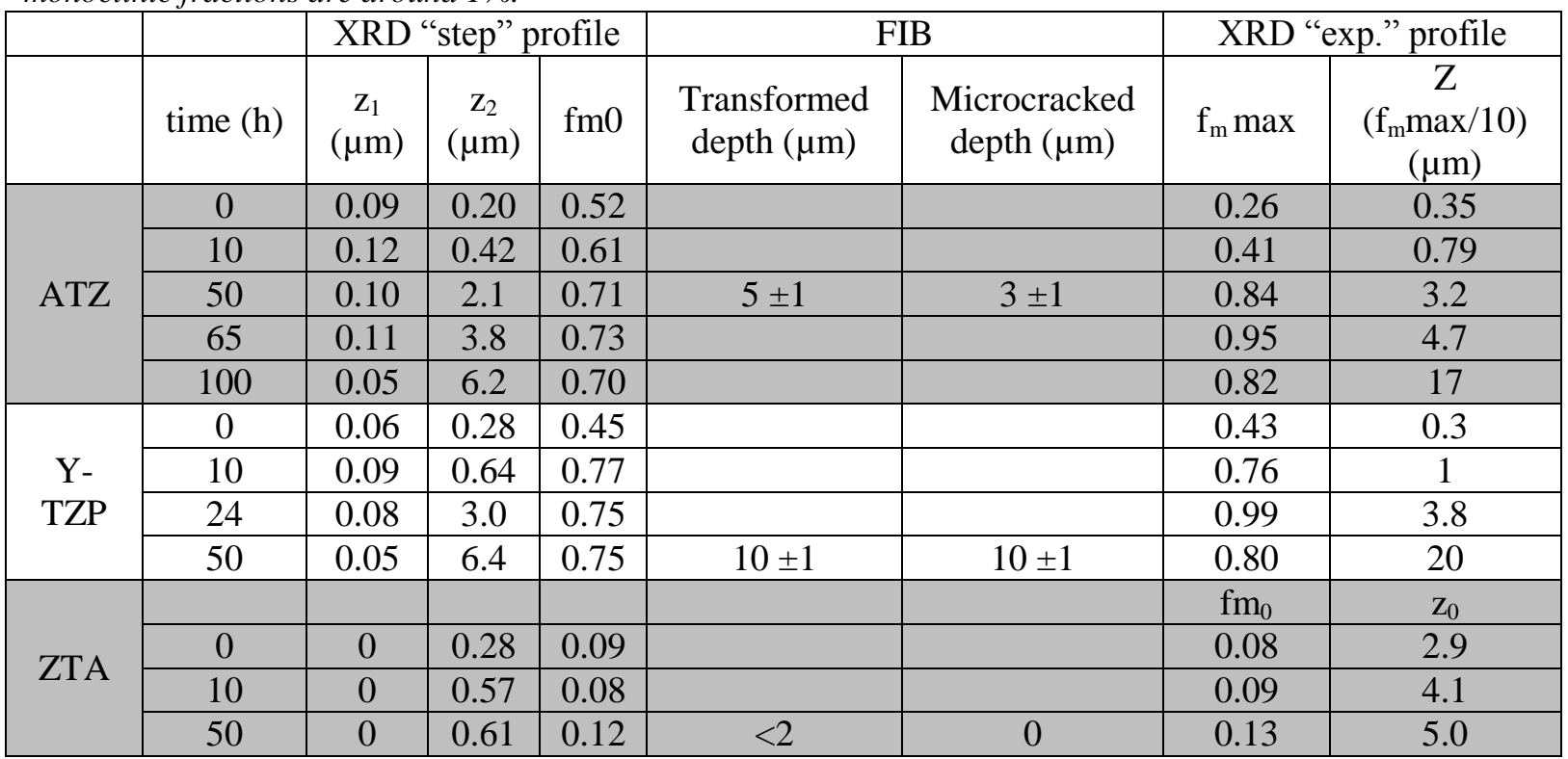

The geometrical parameters describing the shape of the transformed zone obtained by FIB and XRD are reported in Table 3. Hence ATZ and 3Y-TZP (both materials being mainly constituted of zirconia) behave similarly with regard to ageing, in the sense that they present a thin $(\sim 0.1 \mu \mathrm{m})$, non-transformable layer on their surface on top of a completely transformed layer of homogeneous thickness. In addition, the thickness of the transformed layer increases linearly with time, while the monoclinic content in the transformed layer remains stable with time (Figure 10). This is coherent with the low value of $n$ which tends to indicate a fast nucleation of the monoclinic phase[40] (thus the surface is quickly converted into an homogenous layer of monoclinic phase that grows into the volume). This finding is coherent with the work of Keuper et al. [41], affirming that the monoclinic content is constant in the transformed zone, that maximum content only depends on the material (composition, grade and microstructure) and that ageing duration only affects the thickness of this transformed layer which propagates at a constant rate. This results also comfirm previous findings by Le Coadou et al. [42] on 3Y-TZP, who showed the existence of a completely transformed layer of which thickness increases linearly with ageing time at a rate of $\sim 0.05 \mu \mathrm{m} \cdot \mathrm{h}-1$ (comparable to the rates found here: $0.06 \mu \mathrm{m} \cdot \mathrm{h}-1$ for ATZ and $0.13 \mu \mathrm{m} \cdot \mathrm{h}-1$ for $3 \mathrm{Y}-\mathrm{TZP}$, Figure 10). The same rates can be deduced from the data obtained by Kohorst et al. on similar materials [30]. The FIB cross-sections presented here tend to also show homogeneously transformed 
monoclinic layers for ATZ and 3Y-TZP. A clear confirmation would necessitate advanced characterization techniques, such as precession diffraction in TEM (ASTAR) since the more classical EBSD (Electron BackScattered Diffraction) lacks spatial resolution, and Transmission Kikuchi Diffraction (TKD) is too sensitive to residual stresses. However the thicknesses measured by FIB are slightly higher than those calculated by XRD. FIB also points to a significant difference between ATZ and 3Y-TZP: while in 3Y-TZP the whole monoclinic layer contains microcracks, in ATZ microcracks are located only in the upper first half of this layer, just below the surface. This might be due to the lower volume increase induced by the $\mathrm{t}-\mathrm{m}$ transformation in ATZ: since the monoclinic fraction is calculated vs the total zirconia amount, and since ATZ contains only $80 \%$ zirconia, for a given degree of transformation the volume increase in ATZ is $80 \%$ of the volume increase in zirconia.

Moreover in both materials the micro-cracks network is mainly parallel to the surface, and is not highly connected to the surface, similar to other findings [9, 11, 43]. This questions the usual assumption that ageing progresses in the volume because of water progressing to the bulk through the microcracks network. However one must consider the resolution of FIB (in the present study, $3 \mathrm{~nm}$ at best) as compared to the size of a water molecule $(\sim 0.1 \mathrm{~nm})$ : even the most advanced image treatments, such as the ones performed in [43], cannot reveal $0.1 \mathrm{~nm}$ microcracks in FIB reconstructions. Thus a more careful detection of the microcracks network is necessary to conclude on this point. This might not be attainable by microstructural characterization, but rather by diffusion experiments.

Finally, the thin, non-transformable layer is believed to be the result of the presence of machining- or polishing-induced plastification of t-zirconia grains [44]. The presence of a dislocation network may impair the $\mathrm{t}-\mathrm{m}$ transformation, each original tetragonal grain subsequently behaving like a collection of very small domains rather than as a big single grain.

However, one should keep in mind that even if the ageing process seems similar in ATZ and in $3 \mathrm{Y}-\mathrm{TZP}$, it is much slower in ATZ as shown in Figure 3 (b): the quantity of monoclinic phase at a given time is much lower in ATZ.

On the other hand, the degree of transformation in aged ZTA samples decreases gradually from the surface with an exponential behaviour (Figure 11), as a result of the transformation of isolated grains, more numerous close to the surface. This is also favourable for the mechanical resistance as compared to the completely transformed and at least partially microcracked layer found in 3Y-TZP and ATZ. Besides, Figure 3 (b) shows that the amount of monoclinic phase in ZTA is very small, which is not likely to provoke detectable microcracking. 


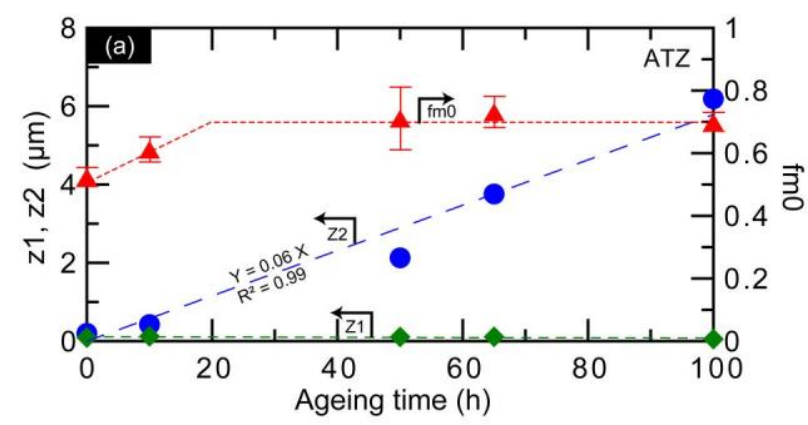

Figure 10 : evolution of the thickness of the transformed layer and of the maximum monoclinic content with time in ATZ (a) and in 3Y-TZP (b). Green diamonds: $z_{1}$; blue disks: $z_{2}$; red triangles: $\mathrm{fm}_{0}$.

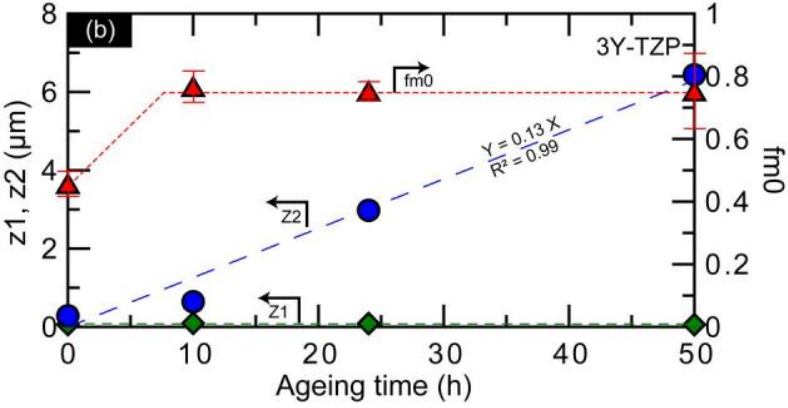
Relative uncertainties on $z_{1}$ and $z_{2}$ are about $5 \%$.
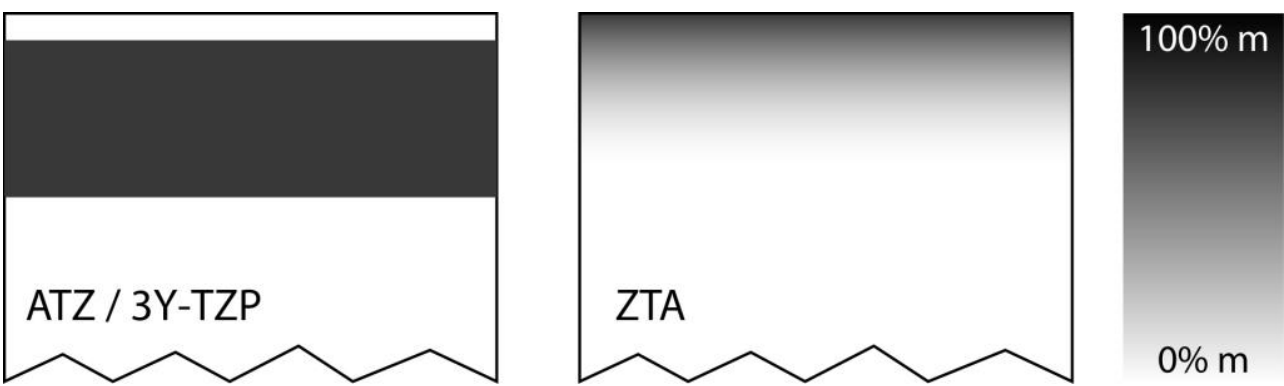

Figure 11 : schematic cross section of the materials after hydrothermal ageing, showing a "step", transformation for ATZ and 3Y-TZP (left) and an exponential decrease of the $m$ content for ZTA (right); darker areas symbolize more transformed areas.

\section{Conclusion:}

This article examines the hydrothermal ageing behaviour of three materials: ATZ, ZTA and the 'benchmark' 3Y-TZP. Results showed that 3Y-TZP and ATZ, the two materials with zirconia as the major phase, behave quite similarly. They both exhibit a three-layered microstructure: a thin $(0.1 \mu \mathrm{m})$ non-transformable layer, above a microcracked, $\sim 70 \%$ monoclinic layer (a few microns thick), above the completely tetragonal bulk. However, ageing in ATZ is around thrice slower at $134^{\circ} \mathrm{C}$ than in $3 \mathrm{Y}$-TZP. Thus the extrapolation of ageing kinetics to body temperature leads to slower kinetics (by a factor of almost 8) for ATZ than what was observed in the literature for 3Y-TZP.

On the other hand, in aged ZTA the maximum monoclinic content is reached on the surface $(\sim 10 \%)$, and the monoclinic content decreases exponentially with depth over a few microns, as the result of the transformation of isolated grains. Combined with the low amount of zirconia in the material $(\sim 25 \%)$, even the most transformed zones do not contain more than $2 \%$ monoclinic phase (in comparison with the total material, alumina included). This low amount of monoclinic plus the very smooth transition between the maximum transformation zone and the bulk material, probably make hydrothermal ageing much less detrimental for the mechanical properties of ZTA than for those of ATZ and 3Y-TZP. However, since the activation energy of ageing in ZTA is lower, longer accelerated ageing times should be used to ascertain this conclusion. 


\section{Acknowledgements}

Thanks are due to the CLYM (Centre Lyonnais de Microscopie: www.clym.fr) for the access to the microscope FIB ZEISS, NVISION 40. CLYM is supported by the CNRS, the "Grand Lyon" and the "Rhône-Alpes Region".

\section{Disclosure}

This research was partly funded by Mathys Orthopaedie $\mathrm{GmbH}$, of which S. Begand, K. Hans and T. Oberbach were employees at the time of the study.

\section{References}

[1] R. Garvie, R. Hanninck, R. Pascoe, Ceramic steel?, Nature 258 (1975) 703-4.

[2] F.F. Lange, Transformation toughening. 1 Size effects associated with the thermodynamics of constrained transformations, J. Mater. Sci. 17 (1982) 225-234.

[3] K. Kobayashi, H. Kuwajima, T. Masaki, Phase change and mechanical properties of ZrO2-Y2O3 solid electrolyte after ageing, Solid State Ionics 3(4) (1980) 489-93.

[4] J. Chevalier, L. Gremillard, A.V. Virkar, D.R. Clarke, The Tetragonal-Monoclinic Transformation in Zirconia: Lessons Learned and Future Trends, J. Am. Ceram. Soc. 92(9) (2009) 1901-1920.

[5] L. Gremillard, L. Martin, L. Zych, E. Crosnier, J. Chevalier, A. Charbouillot, P. Sainsot, J. Espinouse, J.L. Aurelle, Combining ageing and wear to assess the durability of zirconia-based ceramic heads for total hip arthroplasty, Acta Biomater. 9(7) (2013) 7545-7555.

[6] T. Douillard, J. Chevalier, A. Descamps-Mandine, I. Warner, Y. Galais, P. Whitaker, J.J. Wu, Q.Q. Wang, Comparative ageing behaviour of commercial, unworn and worn 3Y-TZP and zirconia-toughened alumina hip joint heads, J. Eur. Ceram. Soc. 32(8) (2012) 1529-1540. [7] J. Chevalier, L. Gremillard, S. Deville, Low-temperature degradation of Zirconia and implications for biomedical implants, Annu. Rev. Mater. Res. 37 (2007) 1-32.

[8] H. Tsubakino, Y. Kuroda, M. Niibe, Surface relief associated with isothermal martensite in zirconia-3-mol\%-yttria ceramics observed by atomic force microscopy, J. Am. Ceram. Soc. 82 (1999) 2921-23.

[9] J.A. Muñoz-Tabares, E. Jiménez-Piqué, M. Anglada, Subsurface evaluation of hydrothermal degradation of zirconia, Acta Mater. 59(2) (2011) 473-484.

[10] M. Cattani-Lorente, S.S. Scherrer, P. Ammann, M. Jobin, H.W. Wiskott, Low temperature degradation of a Y-TZP dental ceramic, Acta Biomater. 7(2) (2011) 858-65. [11] A. Samodurova, A. Kocjan, M.V. Swain, T. Kosmac, The combined effect of alumina and silica co-doping on the ageing resistance of 3Y-TZP bioceramics, Acta Biomater. 11 (2015) 477-87.

[12] V. Lughi, V. Sergo, Low temperature degradation -aging- of zirconia: A critical review of the relevant aspects in dentistry, Dent Mater 26(8) (2010) 807-20.

[13] I.C. Clarke, M. Manaka, D.D. Green, P. Williams, G. Pezzotti, Current status of zirconia used in total hip implants., J. Bone Joint Surg.

Ser. A 85 (2003) 73-84.

[14] K. Haraguchi, N. Sugano, T. Nishii, H. Miki, K. Oka, H. Yoshikawa, Phase transformation of a zirconia ceramic head after total hip arthroplasty, J Bone Joint Surg Br. 83-B (2001) 996-1000.

[15] S.A. Catledge, M. Cook, Y.K. Vohra, E.M. Santos, M.D. McClenny, K.D. Moore, Surface crystalline phases and nanoindentation hardness of explanted zirconia femoral heads, Journal of Materials Sciences: Materials in Medicine 14 (2003) 863-867. 
[16] E.M. Santos, S. Vohra, S.A. Catledge, M.D. McClenny, J. Lemons, K.D. Moore, Examination of surface and material properties of explanted zirconia femoral heads, Journal of arthroplasty 19 (2004) 30-34.

[17] Y.H. Kim, J.S. Kim, Tribological and material analyses of retrieved alumina and zirconia ceramic heads correlated with polyethylene wear after total hip replacement, The Journal of Bone and Joint Surgery (Br) 90(B) (2008) 731-737.

[18] A. Reyes-Rojas, E. Torres-Moye, O. Solís-Canto, A. Aguilar-Elguézabal, M.H. Bocanegra-Bernal, X-ray diffraction and atomic force microscopy study in aged zirconiatoughened alumina composite with dispersion of $\mathrm{m}-\mathrm{ZrO} 2$ nanoparticles, International Journal of Refractory Metals and Hard Materials 35 (2012) 270-278.

[19] P. Fabbri, C. Piconi, E. Burresi, G. Magnani, F. Mazzanti, C. Mingazzini, Lifetime estimation of a zirconia-alumina composite for biomedical applications, Dent Mater 30(2) (2014) 138-42.

[20] G. Pezzotti, T. Saito, G. Padeletti, P. Cossari, K. Yamamoto, Nano-scale topography of bearing surface in advanced alumina/zirconia hip joint before and after severe exposure in water vapor environment, Journal of Orthopaedic Research (2010) n/a-n/a.

[21] J. Chevalier, S. Grandjean, M. Kuntz, G. Pezzotti, On the kinetics and impact of tetragonal to monoclinic transformation in an alumina/zirconia composite for arthroplasty applications, Biomaterials 30(29) (2009) 5279-5282.

[22] J. Chevalier, P. Taddei, L. Gremillard, S. Deville, G. Fantozzi, J.F. Bartolome, C. Pecharroman, J.S. Moya, L.A. Diaz, R. Torrecillas, S. Affatato, Reliability assessment in advanced nanocomposite materials for orthopaedic applications, J Mech Behav Biomed 4(3) (2011) 303-314.

[23] Y. Hirata, Y. Otsubo, Y. Arimura, Dissolution behavior of $\alpha$-alumina in solutions containing Mg2+ ions, Journal of the Ceramic Society of Japan 103(1200) (1995) 782-785. [24] G. Lefèvre, M. Duc, P. Lepeut, R. Caplain, M. Fédoroff, Hydration of <gamma>Alumina in Water and Its Effects on Surface Reactivity, Langmuir 2002(18 ) (2002) 75307537.

[25] S.M. Kurtz, S. Kocagoz, C. Arnholt, R. Huet, M. Ueno, W.L. Walter, Advances in zirconia toughened alumina biomaterials for total joint replacement, J Mech Behav Biomed 31 (2014) 107-16.

[26] A.V. Lombardi, K.R. Berend, B.E. Seng, I.C. Clarke, J.B. Adams, Delta Ceramic-onAlumina Ceramic Articulation in Primary THA: Prospective, Randomized FDA-IDE Study and Retrieval Analysis, Clinical Orthopaedics and Related Research ${ }^{\circledR} 468(2)$ (2009) 367-374. [27] I.C. Clarke, D.D. Green, P.A. Williams, K. Kubo, G. Pezzotti, A. Lombardi, A. Turnbull, T.K. Donaldson, Hip-simulator wear studies of an alumina-matrix composite (AMC) ceramic compared to retrieval studies of AMC balls with 1-7 years follow-up, Wear 267(5-8) (2009) 702-709.

[28] J. Schneider, S. Begand, R. Kriegel, C. Kaps, W. Glien, T. Oberbach, Low-Temperature Aging Behavior of Alumina-Toughened Zirconia, J. Am. Ceram. Soc. 91(11) (2008) 36133618.

[29] T. Oberbach, S. Begand, W. Glien, C. Kaddick, Investigation of aged dispersion ceramics by means of hip simulator, in: G. Daculsi, P. Layrolle (Eds.) 20th International Symposium on Ceramics in Medicine, Key Engineering Materials, Nantes, FRANCE, 2007, pp. 771-74.

[30] P. Kohorst, L. Borchers, J. Strempel, M. Stiesch, T. Hassel, F.W. Bach, C. Hubsch, Lowtemperature degradation of different zirconia ceramics for dental applications, Acta Biomater. 8(3) (2012) 1213-20. 
[31] Y. Kawai, M. Uo, Y. Wang, S. Kono, S. Ohnuki, F. Watari, Phase transformation of zirconia ceramics by hydrothermal degradation, Dental Materials Journal 30(3) (2011) 286292.

[32] R.C. Garvie, P.S. Nicholson, Phases analysis in zirconia systems, J. Am. Ceram. Soc. 55(6) (1972) 303-305.

[33] H. Toraya, M. Yoshimura, S. Somiya, Calibration curves for the quantitative analysis of the monoclinic-tetragonal ZrO2 system by X-ray diffraction, J. Am. Ceram. Soc. 67 (1984)

C119-C121.

[34] J. Chevalier, B. Cales, J.M. Drouin, Low-Temperature Aging of Y-TZP Ceramics, J. Am. Ceram. Soc. 82 (1999) 2150-2154.

[35] L. Gremillard, S. Grandjean, J. Chevalier, A new method to measure monoclinic depth profile in zirconia-based ceramics from X-ray diffraction data, Int J Mater Res 101(1) (2010) 88-94.

[36] V. Boulos, L. Salvo, V. Fristot, P. Lhuissier, D. Houzet, Investigating performance variations of an optimized GPU-ported granulometry algorithm, 18th International European Conference on Parallel and Distributed Computing, Rhodes Island, Greece, 2012.

[37] A. Elmoutaouakkil, L. Salvo, E. Maire, G. Peix, 2D and 3D characterization of metal foams using x-ray tomography, Adv. Eng. Mater. 4 (2002) 803-807.

[38] S. Deville, J. Chevalier, C. Dauvergne, G. Fantozzi, J.F. Bartolome, J.S. Moya, R. Torrecillas, Microstructural investigation of the aging behavior of (3Y-TZP)-Al2O3 composites, J. Am. Ceram. Soc. 88(5) (2005) 1273-1280.

[39] S. Deville, J. Chevalier, G. Fantozzi, J.F. Bartolomé, J.n. Requena, J.S. Moya, R. Torrecillas, L.A. Díaz, Low-temperature ageing of zirconia-toughened alumina ceramics and its implication in biomedical implants, J. Eur. Ceram. Soc. 23(15) (2003) 2975-2982.

[40] L. Gremillard, J. Chevalier, T. Epicier, S. Deville, G. Fantozzi, Modeling the aging kinetics of zirconia ceramics, J. Eur. Ceram. Soc. 24(13) (2004) 3483-3489.

[41] M. Keuper, K. Eder, C. Berthold, K.G. Nickel, Direct evidence for continuous linear kinetics in the low-temperature degradation of Y-TZP, Acta Biomater. 9(1) (2013) 48264835 .

[42] C. Le Coadou, N. Karst, F. Emieux, O. Sicardy, A. Montani, G. Bernard-Granger, J. Chevalier, L. Gremillard, J.P. Simonato, Assessment of ultrathin yttria-stabilized zirconia foils for biomedical applications, J. Mater. Sci. 50(18) (2015) 6197-6207.

[43] E. Jiménez-Piqué, A. Ramos, J.A. Muñoz-Tabares, A. Hatton, F. Soldera, F. Mücklich, M. Anglada, Focused ion beam tomography of zirconia degraded under hydrothermal conditions, J. Eur. Ceram. Soc. 32(10) (2012) 2129-2136.

[44] P.J. Whalen, F. Reidinger, R.F. Antrim, Prevention of Low-Temperature Surface Transformation by Surface Recrystallization in Yttria-Doped Tetragonal Zirconia, J. Am. Ceram. Soc. 72 (1989) 319-321. 